\title{
Retraction Note: Fibrauretine reduces ischemia/reperfusion injury via RISK/eNOS activation
}

\author{
Chunsheng Wang ${ }^{1} \cdot$ Rong Chang $^{1} \cdot$ Gan Gao $^{1} \cdot$ Xing Liu $^{1} \cdot$ Yingwei Zhang $^{1}$ \\ (C) Springer-Verlag GmbH Germany, part of Springer Nature 2020
}

\section{Retraction Note: Naunyn-Schmiedeberg's Arch Pharmacol https://doi.org/10.1007/s00210-019-01770-8}

The Editor in Chief has retracted this article (Wang et al., 2020). After publication concerns were raised about anomalies in some of the data presented in Figs. 4 and 5. The authors have been given the opportunity to submit a new manuscript for peer review.

Author Yingwei Zhang agreed to retraction but has not stated if they agree to this retraction notice. The remaining authors did not respond to any correspondence from the editor or publisher about this retraction.

\section{Reference}

Wang C, Chang R, Gao G, Liu X, Zhang Y (2020) Fibrauretine reduces ischemia/reperfusion injury via RISK/eNOS activation. Naunyn Schmiedeberg's Arch Pharmacol 393:1515-1525. https://doi.org/ 10.1007/s00210-019-01770-8

Publisher's note Springer Nature remains neutral with regard to jurisdictional claims in published maps and institutional affiliations.

The online version of the original article can be found at https://doi.org/ 10.1007/s00210-019-01770-8

Yingwei Zhang

zhangyingwei2118@163.com

1 Shenzhen Longhua District Central Hospital, Shenzhen 518000,

China 